\title{
Land Surface Temperature Anomalies Detection for the Strong Earthquakes in 2018
}

\author{
Azad Rasul ${ }^{1}$ and Luqman W. Omar ${ }^{2}$ \\ 'Department of Geography, Soran University, \\ Kawa Street, Soran 44008, Erbil, Kurdistan Region - F.R. Iraq \\ ${ }^{2}$ Department of Geography, Koya University, \\ Danielle Mitterrand Boulevard, Koya KOY45, Erbil, Kurdistan Region - F.R. Iraq
}

\begin{abstract}
Earthquake every year leads to human and material losses and unpredictability of it by now makes this natural disaster worsen. The objective of the current study was to determine the anomalies in land surface temperature (LST) in areas affected by earthquakes. In this research, three earthquakes $(M>6)$ were studied. Moderate Resolution Imaging Spectroradiometer Aqua and Terra day and night LST data used from 2003 to 2018. The interquartile range (IQR) and mean $\pm 2 \sigma$ methods utilized to select anomalies. As a result, based on the IQR method, no prior and after anomaly detected in selected cases and data. Based on mean $\pm 2 \sigma$, usually positive anomaly occurred during daytime. However, negative (or positive) anomaly occurred during the nighttime before the Mexico and Bolivia earthquakes. During 10 days after the earthquake, sometimes a negative anomaly detected.
\end{abstract}

Index Terms-Anomaly detection, Earthquake, Land surface temperature, Remote sensing.

\section{INTRODUCTION}

One of the most destructive natural disasters is the earthquake which brings enormous losses to humankind (Geiß and Taubenböck, 2013). International seismology and remote sensing community considered utilizing remote sensing (data) for monitoring of earthquake as a promising research area (Tronin, 2009). Ground stations data for earthquakes represent only a small extent. Therefore, compared to traditional approaches of seismic monitoring, satellite data have numerous advantages (Jiao, Zhao and Shan, 2018). During 2018, 134 earthquakes $(M>6)$ occurred around the world (USGS.gov, 2019). However, optical satellite data also have disadvantages, such as cloud cover. Therefore, three examples of them in clear sky atmospheres selected for the current research.

Many signs of earthquake can be monitored by referring to prevailing temperature of underground water, near-surface

\section{ARO-The Scientific Journal of Koya University}

Vol. VIII, No.2 (2020), Article ID: ARO.10591, 7 pages

DOI:10.14500/aro.10591

Received: 15 November 2019; Accepted: 07 August 2020

Regular research paper: Published: 01 September 2020

Corresponding author's e-mail: azad.rasul@soran.edu.iq

Copyright (C) 2020 Azad Rasul, Luqman W. Omar. This is an openaccess article distributed under the Creative Commons Attribution License. air temperature, radon, and greenhouse gas. Moreover, the dominant parameters of temporal-spatial magnitude of the earthquake are an anomaly of satellite thermal infrared, temperature, and ionosphere disturbances ( $\mathrm{Wu}$ and Liu, 2009). Tramutoli, et al. (2001) and Tronin, Hayakawa and Molchanov (2002) detected up to $5^{\circ} \mathrm{C}$ temperature increase before the earthquakes in Italy, Japan, and China. An increase in land surface temperature (LST) and a decrease in sea surface temperature observed in the Gujarat earthquake in India by Ouzounov and Freund (2004). Furthermore, Ouzounov, et al. (2018) discovered infrared signals such as outgoing longwave radiation (OLR) hotspots several days before some earthquakes near the epicentre. Approximately 7-8 days before the major earthquake, OLR anomaly can increase $30-45 \mathrm{Wm}^{-2}$ around epicentral areas (Rawat, et al., 2011). Zoran Savastru and Savastru (2015) discerned the development of spatiotemporal prior anomaly of LST, OLR, and mean air temperature parameters related to strong earthquakes in Romania.

Despite productive research in this field, still, uncertainty and arguments remain about pre-seismic anomaly detection due to some crucial misinterpretations and failure earthquake forecasting (Geller, 2011; Tronin, 2009). The seismic community still not completely accepted seismic precursor because it is not perfectly formed (Geller, 1997; Geller, et al., 1997). Earthquake prediction to be trusted should be based on scientific methods, the data should be accessible to researchers and earthquake-related signs should be well documented. Besides, the research should specify the spatiotemporal and magnitude window and researcher level of confidence in the prediction and chances of occurring earthquake (Allen, 1976; Geller, 1997). Jiao, Zhao and Shan (2018) suggested that reliability of earthquake forecasting could be intensified by utilizing combined application and multiparameter analysis.

In this research, we utilize both Aqua and Terra LST data of day and night because having an anomaly in many parameters before the earthquakes in the same area, capable to make temperature anomaly that associated with earthquake more trustful and realistic. To save time and efforts in processing LST long time series data, the code script of cloud-based remote sensing platform Google Earth Engine 
(GEE) was prepared and utilized. In addition, we observed that detecting the earthquake anomaly by utilizing only one statistical method is not robust (Bhardwaj, et al., 2017), in this study, therefore, two methods, namely, interquartile range (IQR) and mean $\pm 2 \sigma$ were utilized to improve the efficiency of anomalous difference. This study is important because select LST anomaly in robust technique can have many implications in terms of monitoring earthquakes and its consequences.

The objective of the current study was to determine the earthquake's remote sensing LST anomaly by utilizing GEE with $\mathrm{R}$ programming. Three samples of the earthquake in the land transparent sky were considered. The research divided into five sections. The first section is introduction that includes background and literature review. The second section includes explanation of materials and methods used in the research. In the next section, results displayed then we discussed our results compared to other researches. The paper concluded with some conclusion that created from the research.

\section{Materials And Methods}

\section{A. Data}

Moderate Resolution Imaging Spectroradiometer (MODIS) is one of the main sources of earth observation research. Aqua satellite orbits the earth from south to north at 1:30 P.M. local time whereas Terra passes in the opposite direction at 10:30 A.M. local time. Both of them use 36 spectral bands (from 0.415 to $14.235 \mu \mathrm{m}$ ) in senses the surface (Shen, et al., 2013). LST is the radiative temperature of the land surface which typically surveyed by remote sensing. The resolution of selected LST MODIS data is $1 \mathrm{~km}$ (Rasul, Balzter and Smith, 2016). In this research, both Aqua and Terra day and night LST data used from 2003 to 2018 (Table I).

\section{B. Study Sites}

In this research, three strong earthquakes were assessed which occurred during 2018 around the world (Table II). Included earthquakes are higher than six magnitudes.
Because the cloudy condition is a significant problem for active remote sensing, samples were selected in the land with transparent sky situations (Fig. 1).

\section{Methodology}

\section{C.1. Downloading and processing data}

Several studies designate that earthquake anomaly within a few days to a few weeks before the seismic events could be considered as short-term precursors (Jiao, Zhao and Shan, 2018). Therefore, in this study, 20 days before and 10 days after the main shake selected as temporal window. In this study, four overpasses LST data (Table I) processed in GEE (Appendix A) (Gorelick, et al., 2017). The data collection and interested band and interested period selected. One month data selected for each year, the year from 2003 to 2018. Past years' data of 20 days before and 10 days after the main quake have been included in the analyses to characterise anomalies. Images were cropped to study site and LST values are multiplied by a scale factor. Then, the data were exported as CSV file.

\section{C.2. Anomaly detection}

Anomaly detected and graphs created in R programming using packages such as "anomalize," "devtools," "coindeskr," "dplyr," and "ggplot2" (Appendix B). To detect anomalies in the time series of the data, two methods were utilized. The first one is the IQR which utilizes a range of 25 the median (Dancho and Vaughan, 2018). In this method, negative anomaly LST outliers are values that smaller than limit lower whereas positive anomaly LST is values that bigger than limit upper. The same as a boxplot, the whiskers are lines ranging from Q1 and Q3 to ends. Limit lower calculated by Q1 - 1.5 × IQR and upper limit calculated by Q3 $+1.5 \times$ IQR (Streit and Gehlenborg, 2014).

Moreover, the second method is mean $\pm 2 \sigma$ (equation 1 ). In this rule, $95 \%$ of values drop between (mean- $2 * \sigma$, mean $+2 * \sigma$ ) (anomaly.io, 2015). Some researchers (e.g., [Dey and Singh, 2003]) used mean $+1.5^{*} \sigma$ of parameter as background noise. Besides, $\mathrm{Wu}$, et al. (2016) used "mean $\pm 1.5^{*} \sigma$ " and "mean $\pm 2 * \sigma$ " for seismic precursor parameters such as soil moisture, soil temperature, and near

TABLE I

Detalls of the Utilized Data in the Research

\begin{tabular}{|c|c|c|c|c|c|c|}
\hline Data & Temporal resolution & Spatial resolution & Start date & End date & Image collection ID in GEE & Selected band \\
\hline Daytime LST (Terra) & 1 day & $1000 \mathrm{~m}$ & January 1,2003 & 1 May 2018 & MODIS/006/MOD11A1 & LST_Day_1 km \\
\hline Nighttime LST (Terra) & 1 day & $1000 \mathrm{~m}$ & January 1,2003 & 1 May 2018 & MODIS/006/MOD11A1 & LST_Night_1 km \\
\hline Daytime LST (Aqua) & 1 day & $1000 \mathrm{~m}$ & January 1, 2003 & 1 May 2018 & MODIS/006/MYD11A1 & LST_Day_ $1 \mathrm{~km}$ \\
\hline
\end{tabular}

LST: Land surface temperature, MODIS: Moderate Resolution Imaging Spectroradiometer

TABLE II

Details of the Studied Earthquakes

\begin{tabular}{lllccc}
\hline \hline S. No. & Location & Date & Epicentre & Magnitude (USGS) & Focal depth (km, USGS) \\
\hline 1 & San Pedro Jicayan, Mexico & Febaury 16, 2018 & $16.386 \mathrm{~N}, 97.979 \mathrm{~W}$ & 7.2 & 22 \\
2 & Carandayti, Bolivia & April 2, 2018 & $20.659 \mathrm{~S}$, 63.006 W & 6.8 & 559 \\
3 & Jarm, Afghanistan & January 31, 2018 & $36.526 \mathrm{~N}, 70.851 \mathrm{E}$ & 6.2 & 193.7 \\
\hline \hline
\end{tabular}




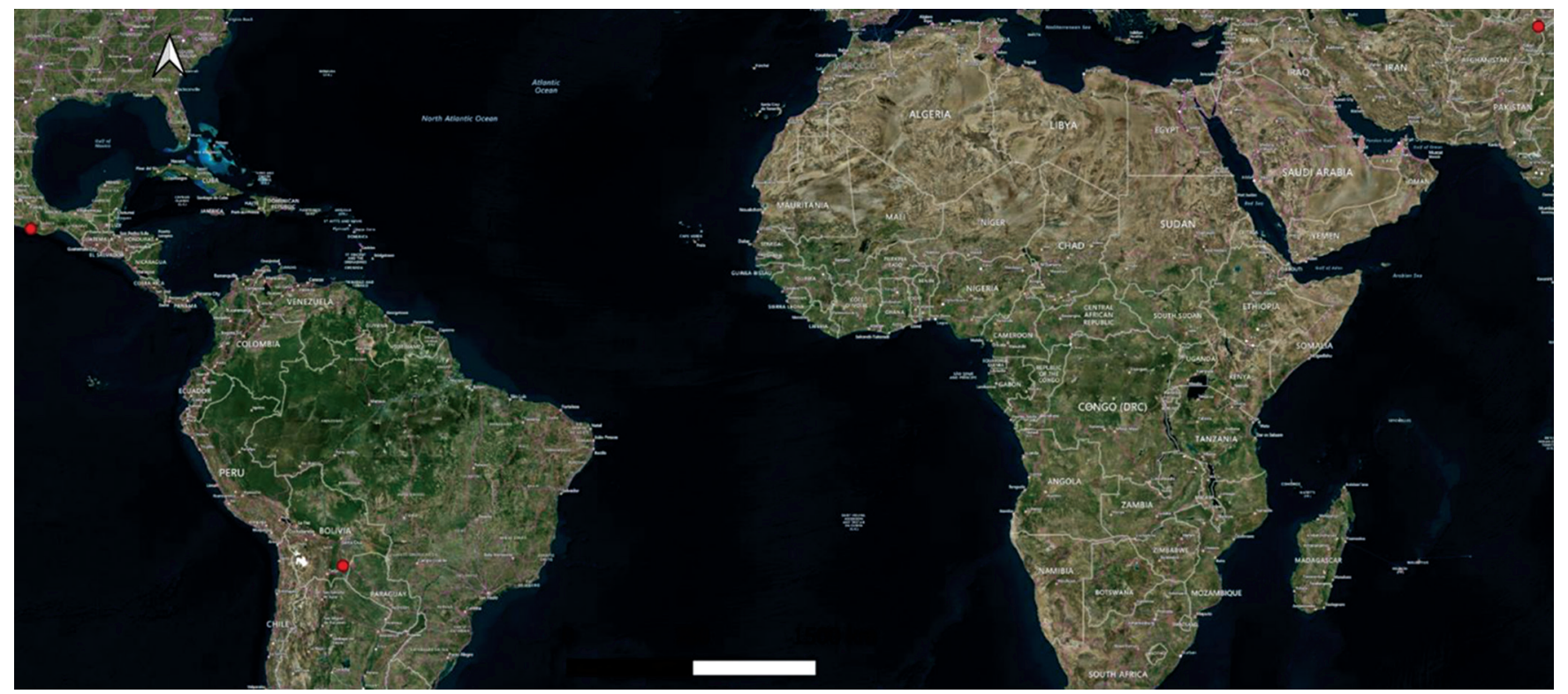

Fig. 1. Locations of studied earthquakes. Red stars are the epicentre of the earthquakes.

surface air temperature. In this study, as cautious only two standard deviations considered as anomaly.

Anomaly $=$ mean $\pm(2 \sigma)$

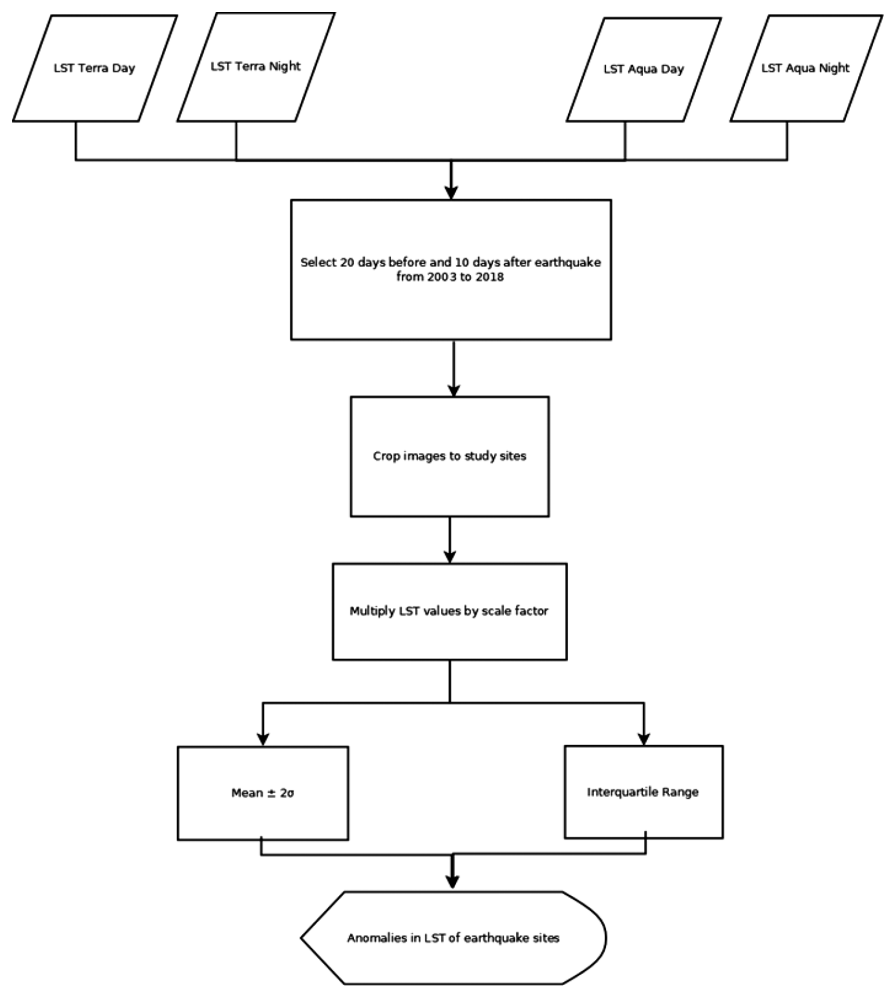

\section{RESULTS}

LST data of 20 days before and 10 days of data after the quack analyzed for each selected earthquake in Mexico, Bolivia, and Afghanistan during 2018. Both used methods for anomaly detection in LST time series displayed in the following figures. MODIS LST for Aqua and Terra has 4 times passed per day; therefore, they displayed separately in the following in subfigure $\mathrm{a}, \mathrm{b}, \mathrm{c}$, and $\mathrm{d}$.

\section{A. Mexico Earthquake on Febaury 16, 2018}

Based on IQR method, no anomaly detected in LST Aqua and Terra of both day and night data in the Mexico (Fig. 2b), Bolivia (Fig. 3a and b), and Afghanistan earthquakes during 20 days before and 10 days after the earthquakes (Fig. $4 \mathrm{a}$ and b). According to mean $\pm 2 \sigma$, in Aqua night, positive anomaly detected. In Terra day LST data, negative anomaly detected 14 and 16 days before the quake (Fig. 2c). Furthermore, positive anomaly occurred 2 days before the Mexico earthquake. After the quake, negative anomaly occurred in Aqua day and Terra night data (Fig. 2a and d). Occurred negative anomaly some days after the quack perhaps explained by returning the area to stability. In Fig. 2d, some values passed lower limits (dotted red lines), but these anomalies occurred during previous years and during 2018, no anomaly detected based on interquartile outliers.

\section{B. Bolivian Earthquake on April 2, 2018}

Concerning Bolivian earthquake, no anomaly detected based on IQR. However, based on mean $\pm 2 \sigma$ methods in Aqua night (Fig. 3b) and Terra day and night LST (Fig. 3c and $\mathrm{d}$ and Table III), prior negative anomaly detected. Duration of detected anomalies is between 5 days and 11 days before the main shake and the degree decreased between -6.9 and $-13.1 \mathrm{~K}$. The upper limit in IQR is higher than mean plus two standard deviations. Besides, lower limit based on IQR smaller than lower limit based on mean minus two standard deviations. Therefore, the second method is more capable in detect anomaly in LST time series.

\section{Afghanistan Earthquake on January 31, 2018}

According to mean $\pm 2 \sigma$ method, prior positive anomaly detected 10 and 11 days before Afghanistan earthquake (January 31, 2018) in MODIS Terra daytime (Table III). These 

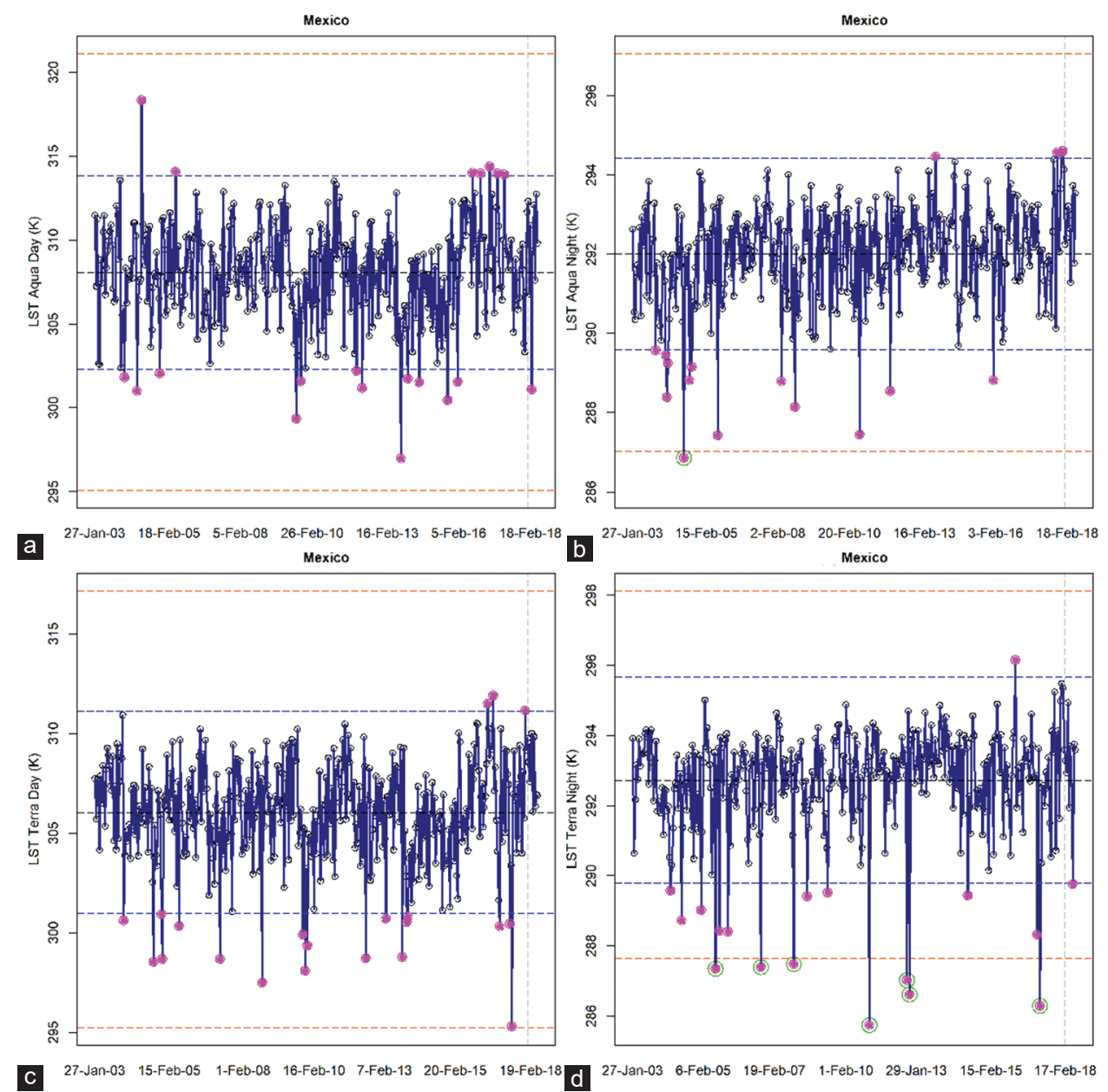

Fig. 2. Temporal anomalies of land surface temperature (LST) Aqua day (a), LST Aqua night (b), LST Terra day (c), LST Terra night (d), in San Pedro Jicayan, Mexico earthquake (February 16, 2018). Gray dashed line: The day of the earthquake, blue dashed lines: Limit upper and limit lower based on mean $\pm 2 \sigma$, red dashed lines: Limit upper and limit lower based on interquartile range (IQR) method, magenta circles: Anomaly based on mean $\pm 2 \sigma$, green circle: IQR-based anomalies, black dashed line: Mean value of the area.

TABLE III

Anomalies in Mexico (February 16, 2018), Bolivia (April 2, 2018), and Afghanistan (January 31, 2018) EarthquaKes With the Intensity and Type of Anomaly and How Many Days before or after the Main Quake Anomaly Occurred

\begin{tabular}{|c|c|c|c|c|c|c|}
\hline Earthquake & Data & IQR method & Mean $\pm 2 \sigma$ method & Type & Compare to mean & Days before \\
\hline \multirow[t]{3}{*}{ Mexico } & Terra night & No & Yes & Post (negative) & -3 & (8 after) \\
\hline & Aqua night & No & Yes & Prior positive & $2.6,2.6,2.6$ & $2,3,8$ \\
\hline & Terra day & No & Yes & Prior positive (negative) & $5.1,-10.7,-5.6$ & $2,14,16$ \\
\hline \multirow[t]{3}{*}{ Bolivia } & Terra night & No & Yes & Prior negative & -6.9 & 5 \\
\hline & Aqua night & No & Yes & Prior negative & $-13.1,-7.8,-9.7$ & $4,5,11$ \\
\hline & Terra day & No & Yes & Prior negative & $-9.8,-9.2$ & 5,9 \\
\hline \multirow[t]{4}{*}{ Afghanistan } & Terra night & No & No & & & \\
\hline & Aqua night & No & No & & & \\
\hline & Terra day & No & Yes & Prior positive & $10.5,10.2$ & 10,11 \\
\hline & Aqua day & No & No & & & \\
\hline
\end{tabular}

outliers were larger than mean by 10.5 and $10.2 \mathrm{~K}$ degrees. In Aqua day and night data, no anomalies detected. Based on quartile outliers, no outliers detected in Aqua and Terra, daytime and nighttime LST data in this case study neither during 2018 nor previous years in the same period (Fig. 4 a-d).

\section{DisCUSSION}

Nezammahalleha, et al. (2013) and Saraf, et al. (2008) found more seismic activity occurred in areas with higher LST in Iran and positive anomaly of LST observed in 23 Indian earthquakes. The current research used daytime 

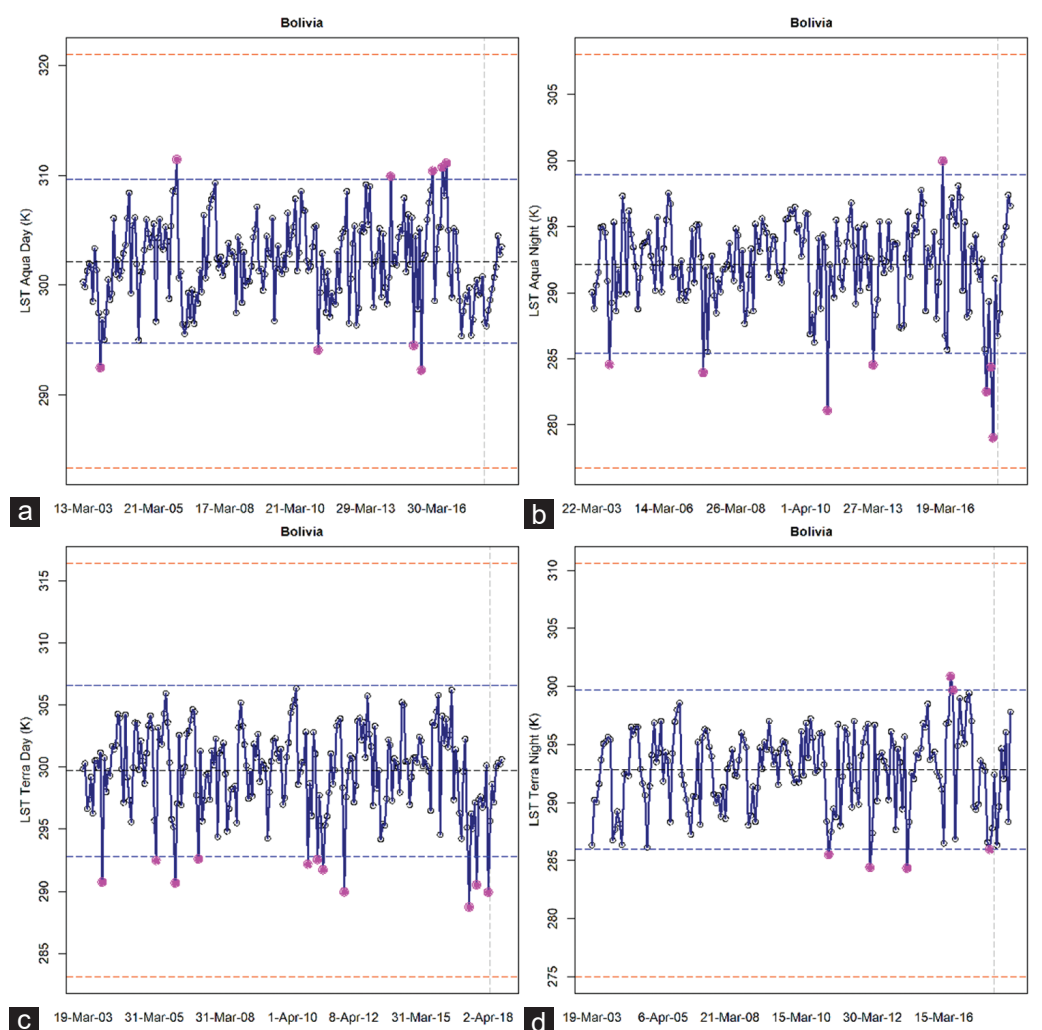

d

19-Mar-03 6-Apr-05 21-Mar-08 15-Mar-10 30-Mar-12 15-Mar-16

Fig. 3. Temporal anomalies of land surface temperature (LST) Aqua day (a), LST Aqua night (b), LST Terra day (c), LST Terra night (d), in Carandayti, Bolivian earthquake (April 2, 2018). Gray dashed line: The day of the earthquake, blue dashed lines: Limit upper and limit lower based on mean $\pm 2 \sigma$, red dashed lines: Limit upper and limit lower based on interquartile range (IQR) method, magenta circles: Anomaly based on mean $\pm 2 \sigma$, green circle: IQR-based anomalies, black dashed line: Mean value of the area.
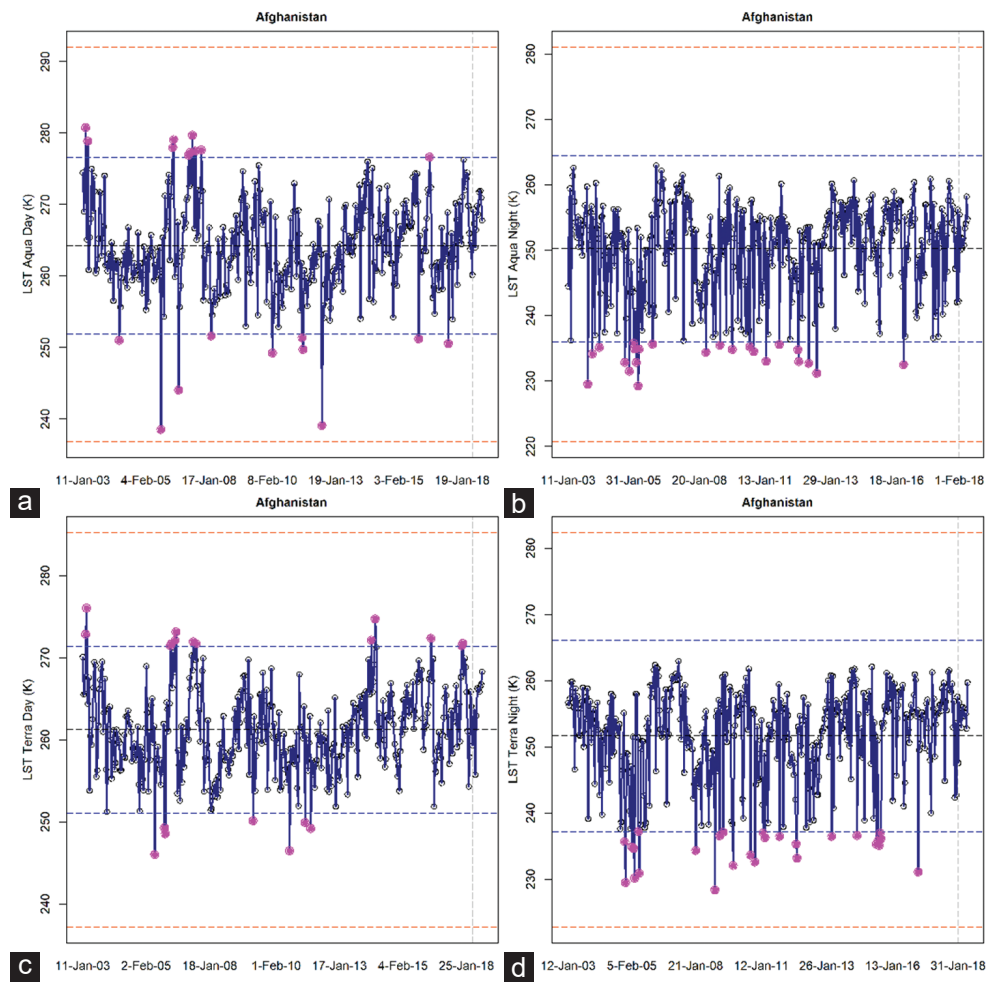

Fig. 4. Temporal anomalies of land surface temperature (LST) Aqua day (a), LST Aqua night (b), LST Terra day (c), LST Terra night (d), in Jarm, Afghanistan earthquake (January 31, 2018). Gray dashed line: The day of the earthquake, blue dashed lines: Limit upper and limit lower based on mean $\pm 2 \sigma$, red dashed lines: Limit upper and limit lower based on on interquartile range (IQR) method, magenta circles: Anomaly based on mean $\pm 2 \sigma$, green circle: IQR-based anomalies, black dashed line: Mean value of the area. 
and nighttime MODIS LST data. It found usually positive anomaly of LST during daytime however negative (or positive) anomaly during the nighttime LST data before the earthquakes. After the earthquake during 10 days, a negative anomaly could be anticipated in both Aqua and Terra LST. As a result of investigated three samples of an earthquake during 2018, we observed in some earthquakes, anomaly in more than 1 parameter discerned such as Mexico and Bolivia. Whereas in some earthquake such as Afghanistan earthquake, only prior anomaly occurred in daytime Terra LST.

In LST Terra daytime, positive anomaly was detected in the $20^{\text {th }}$ and $21^{\text {st }}$ of January, which means 10 and 11 days before the earthquake of Afghanistan (Fig. 4c). However, also outliers detected during 2003, 2006, 2007, 2011, 2012, 2014, and 2018. It implies that perhaps occurring anomaly in LST during this period is not completely related to the earthquake. The relationship between longtime data of climatic parameters and dates of earthquakes required more investigations to disclose whether the anomalies related to earthquake or it happened by other factors. Our results confirm that method of mean and two standard deviations is more capable to find anomaly compared to IQR method to select outliers in LST.

\section{CONCLusions}

The current study aimed to determine the earthquake's remote sensing LST temporal anomaly of samples of earthquake occurred during 2018. Samples of the earthquake in the land transparent sky considered. Four times MODIS data that available through GEE used and analyzed using GEE with $R$ programming.

In Bolivian earthquake, based on mean $\pm 2 \sigma$ anomaly methods, prior anomaly detected in Aqua night and Terra LST. Based on the IQR method, anomaly of LST not detected in assessed cases. Whereas based on mean $\pm 2 \sigma$ anomaly, positive or negative anomaly of LST occurred during daytime and nighttime. However, negative anomaly detected after the Mexico earthquake.

Researches in this field may have some limitations, for instance, some parameters available on the GEE, but they are not real-time data. Some satellite data are available in GEE but they have not high resolution. Besides, some anomaly detected around the earthquake period, may not relate to the occurred earthquake because of anomalies discerned during the same month of previous years. Another problem of earthquake forecasting is falsenegative case. Future research should focus on other reliable factors that perhaps related to an earthquake. They should utilize more techniques and statistical methods for discovering robust results that may contribute to forecast an earthquake in the future. Conclusively, use of four LST data from different times of day and night in the current study led to more insight about LST anomaly related to earthquake.

\section{ACKNOWLEDGMENT}

The authors would like to acknowledge the GEE program and the R Development Core Team to support and support this freely available program.

\section{REFERENCES}

Allen, C.R., 1976. Responsibilities in earthquake prediction: To the seismological society of America, delivered in Edmonton, Alberta, May 12, 1976. Bulletin of the Seismological Society of America. 66(6), pp.2069-2074.

Anomaly.Io., 2015. Anomaly Detection with the Normal Distribution, Anomaly. Available from: https://www.anomaly.io/anomaly-detection-normal-distribution. [Last accessed on $2019 \mathrm{Jul} 14]$.

Bhardwaj, A., Singh, S., Sam, L., Bhardwaj, A., Martín-Torres, F.A., Singh, A., and Kumar, R., 2017. MODIS-based estimates of strong snow surface temperature anomaly related to high altitude earthquakes of 2015. Remote Sensing of Environment, 188, pp.1-8.

Dancho, M., and Vaughan, D., 2018. Anomalize: Tidy Anomaly Detection. Available from: https://www.cran.r-project.org/package=anomalize. [Last accessed on 2019 Jan 03].

Dey, S., and Singh, R.P. 2003. Surface latent heat flux as an earthquake precursor. Natural Hazards and Earth System Science, 3(6), pp.749-755.

Geiß, C., and Taubenböck, H., 2013. Remote sensing contributing to assess earthquake risk: From a literature review towards a roadmap. Natural Hazards, 68(1), pp.7-48.

Geller, R.J., 1997. Earthquake prediction: A critical review. Geophysical Journal International, 131(3), pp.425-450.

Geller, R.J., 2011. Shake-up time for Japanese seismology. Nature, 472, pp.407-409.

Geller, R.J., Jackson, D.D., Kagan, Y.Y., and Mulargia, F., 1997. Earthquakes cannot be predicted. Science, 275(5306), pp.1616-1616.

Gorelick, N., Hancher, M., Dixon, M., Ilyushchenko, S., Thau, D., and Moore, R., 2017. Google earth engine: Planetary-scale geospatial analysis for everyone. Remote Sensing of Environment, 202, pp.18-27.

Jiao, Z.H., Zhao, J., and Shan, X., 2018. Pre-seismic anomalies from optical satellite observations: A review. Natural Hazards and Earth System Sciences, 18(4), pp.1013-1036.

Nezammahalleha, M.A., Noori, A.A., Afsharmanesh, H., Pourhosseini, Z., Rastegar, A., Rezai, H.S.S., and Alavipanah, S.K., 2013. Identification of active areas of earthquake by thermal remote sensing. International Archives of the Photogrammetry, Remote Sensing and Spatial Information Sciences, 1, pp.295-299.

Ouzounov, D., and Freund, F., 2004. Mid-infrared emission prior to strong earthquakes analyzed by remote sensing data. Advances in Space Research, 33(3), pp.268-273.

Ouzounov, D., Pulinets, S., Kafatos, M.C., and Taylor, P., 2018. Thermal radiation anomalies associated with major earthquakes. In: Pre-Earthquake Processes: A Multidisciplinary Approach to Earthquake Prediction Studies, Geophysical Monograph. Vol. 234. John Wiley, Hoboken, pp.259-274.

Rasul, A., Balzter, H., and Smith, C., 2016. Diurnal and seasonal variation of surface urban cool and heat Islands in the Semi-Arid City of Erbil, Iraq. Climate, 4(3), p.42.

Rawat, V., Saraf, A.K., Das, J., Sharma, K., and Shujat Y., 2011. Anomalous land surface temperature and outgoing long-wave radiation observations prior to earthquakes in India and Romania. Natural Hazards, 59(1), pp.33-46.

Saraf, A.K., Choudhury, S., Rawat, V., Banerjee, P., Dasgupta, P., and Das, J.D., 2008. Detecting earthquake precursor: A thermal remote sensing approach. In: Map India 2008-11 th Annual International Conference and Exhibition on Geospatial Information, Technology and Application. pp.1-10. 
Shen, H., Li, X., Zhang, L., Tao, D., and Zeng, C., 2013. Compressed sensingbased inpainting of aqua moderate resolution imaging spectroradiometer band 6 using adaptive spectrum-weighted sparse Bayesian dictionary learning. IEEE Transactions on Geoscience and Remote Sensing, 52(2), pp.894-906.

Streit, M., and Gehlenborg, N., 2014. Bar charts and box plots. Nature Methods, 11(2), p.117.

Tramutoli, V., Bello, G.D., Pergola, N., and Piscitelli, S. 2001. Robust satellite techniques for remote sensing of seismically active areas. Annals of Geophysics, 44, pp.295-312.

Tronin, A., 2009. Satellite remote sensing in seismology. A review. Remote Sensing, 2(1), pp.124-150.

Tronin, A.A., Hayakawa, M., and Molchanov, O.A., 2002. Thermal IR satellite data application for earthquake research in Japan and China. Journal of
Geodynamics, 33(4-5), pp.519-534.

USGS.Gov., 2019. USGS Earthquake Hazards Program. Available from: https:// www.earthquake.usgs.gov. [Last accessed on 2019 Jul 14].

Wu, L., and Liu, S., 2009. Remote sensing rock mechanics and earthquake thermal infrared anomalies. In: Advances in Geoscience and Remote Sensing. Intech Open, London.

Wu, L., Zheng, S., Santis, A.D., Qin, K., Mauro, R.D., Liu, S., and Rainone, M.L., 2016. Geosphere coupling and hydrothermal anomalies before the 2009 Mw 6.3 L'Aquila earthquake in Italy. Natural Hazards and Earth System Sciences, 16, pp.1859-1880.

Zoran, M.A., Savastru, R.S., and Savastru, D.M., 2015. Satellite thermal infrared anomalies associated with strong earthquakes in the Vrancea area of Romania. Open Geosciences, 7(1), pp.606-617.

\section{APPENDIXES}

\section{APPENDIX A: A sample of process data in the google engine code}

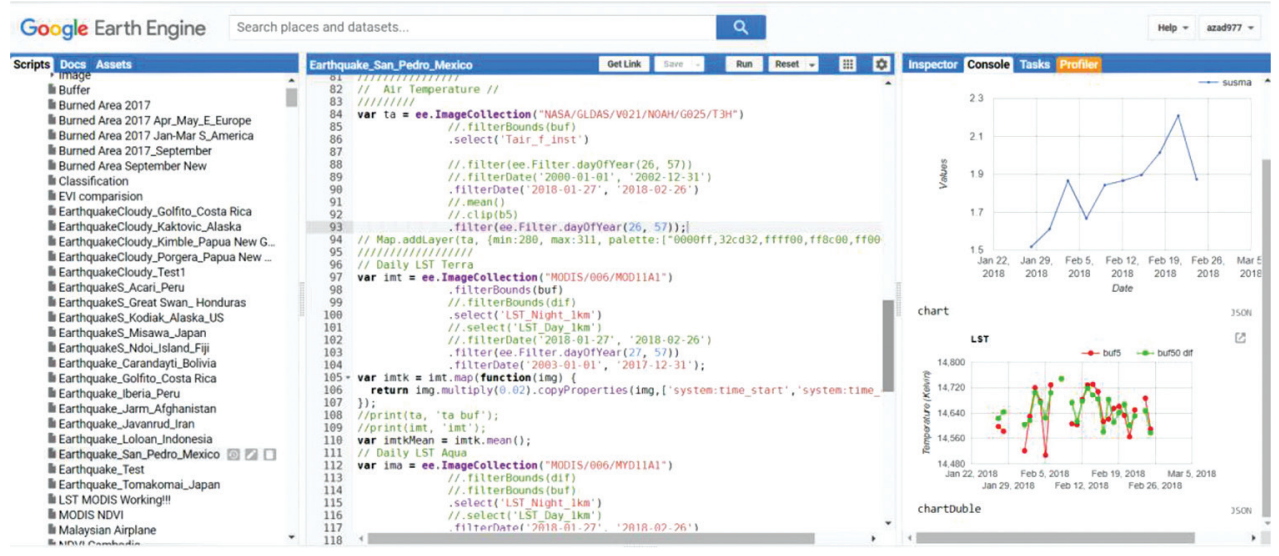

APPENDIX B: A sample of utilized $R$ code in the study

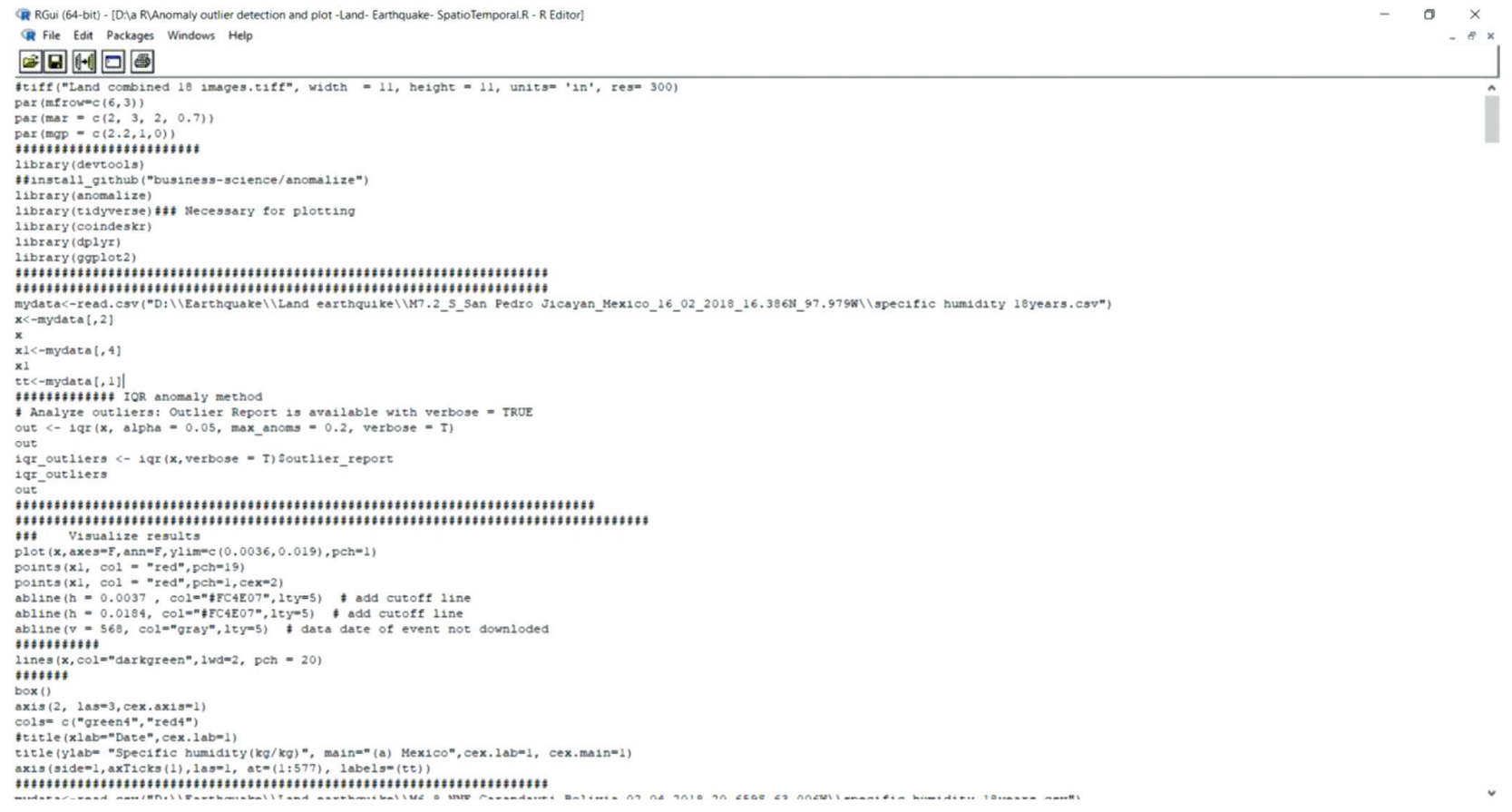

